\title{
The use of an unstaffed flat for crisis intervention and rehabilitation
}

\author{
Douglas TuRkington, Senior Registrar, Department of Psychiatry, Royal Hallamshire \\ Hospital, Glossop Road, Sheffield S10 2JF (correspondence); DAVID KINGDON, \\ Consultant Psychiatrist, Bassetlaw District General Hospital, Worksop; and KaTY \\ Malcolm, Lecturer, Department of Psychiatry, Northern General Hospital, Sheffield
}

The community psychiatry service in Bassetlaw District has been developing since 1984 and provision includes hospital hostels, supervised flatlets, nursing and rest homes, group homes, cluster flats and warden assisted accommodation. Close liaison with an enthusiastic Local Authority Housing Department has also led to the development of a new initiative, an unstaffed flat for use in crisis intervention and rehabilitation. Placements in the flat are described over the first 12 months of its existence.

\section{The setting}

The flat is situated in an attractive residential housing scheme within walking distance of Bassetlaw District General Hospital where the acute ward ( 30 beds) and the Day Hospital (35 places) are located. It consists of the upper floor of an end terraced house with its own small garden. Accommodation comprises entrance hall, living room, kitchen and one bedroom. Responsibility for keeping the flat tidy was left with the residents with the help of Domiciliary Services between each patient entry. The care of the garden was mostly undertaken by clients who were working community service orders as part of their probation. It was agreed prior to its opening that there would be no staff in residence but that a telephone would be available in the flat by which nursing staff on the acute ward could be contacted, and from there consultation could occur with the on-call psychiatrist if this was deemed necessary. It was decided that no patient would be allowed to remain in the flat for longer than 15 days on any one entry.

\section{The residents}

Over the first 12 months a total of 15 admissions were made into the flat. These were organised by members of the multidisciplinary team but all cases were discussed with the consultant psychiatrist responsible for the care before entry. The average length of stay in the flat was 12 days with a range of $1-15$ days. The high average length of stay indicates a high level of acceptability and that inappropriate placements were only rarely made. The average age of the residents was 36.7 years with a range of $18-65$ years and a standard deviation of 12.3 years. Although the flat is situated in the town of Worksop (population 40,000 ), patients from throughout the district were able to make use of the facility. Of the 15 admissions into the flat over the study period, eight were rehabilitative in nature and seven were crisis interventions. Source of referral, diagnosis based on ICD-9 (World Health Organization, 1978) and outcome are reported below.

\section{The rehabilitation group}

Patients were placed in the flat from the hospital hostels, the acute ward and direct from the community. Two long-stay patients from the hospital hostel (one with schizoaffective psychosis and another with depressive neurosis) were transferred to the flat following intensive rehabilitation. In one case the ability to cope with independent living was confirmed but in the other a need for a more supervised setting was apparent. The acute ward provided three patients (two with manic depressive psychosis and one with paranoid state). Discharge directly home was impossible due to rapid relapse precipitated by high levels of expressed emotion. In two cases a move to independent living was successfully achieved and in the other the offer of a sheltered flat was accepted. The three patients from the community (two with schizophrenia and one with asthenic personality disorder and alcoholism) were admitted into the flat in the hope of breaking the stranglehold of parental over-protection and criticism. Two of these placements failed but the other resulted in symptomatic improvement and a move on to a supervised flat.

\section{The crisis intervention group}

Admission to the flat was organised in all cases directly from the community. The diagnosis of manic depressive psychosis was made in three instances, and 
other diagnoses included schizophrenia, depressive neurosis, alcohol dependence and acute stress reaction. Life events of various types produced new symptoms or caused deterioration of pre-existing ones. Marital tensions were at the root of five of the crisis admissions and a period of 'time out' was often all that was required to initiate symptomatic improvement. No alterations were made to the medication which patients had been on prior to admission. All patients were encouraged to continue to attend group and individual psychotherapy sessions as previously arranged and extra support was given if needed by the staff member who organised the admission. In all cases removal from the source of the crisis led to symptomatic improvement once adequate support and appropriate psychotherapy had been initiated.

\section{Comment}

This paper shows that an unstaffed crisis/rehabilitation flat is a useful adjunct to a district community psychiatric service. The use of the flat in two such different modes, appeared to work extremely well and allowed occupancy to be kept at a high level. To our knowledge, there are no other reports in the literature of an unstaffed flat being used in this way as a final rehabilitative step on the journey from institutional care to the appropriate level of supervised/ independent existence in the community. The relationship between high expressed emotion and prognosis has been well explored in the case of schizophrenia (Leff et al, 1982). The rehabilitation needs of this group of patients may not be best met in the Day Hospital without alternative accommodation but can be effectively assessed in terms of symptomatic response in the flat. Only two cases were complete failures. In all other cases successful outcome in terms of placement (four cases), or in terms of symptomatic improvement or learning experience (two cases) was achieved.

In comparison, much work has been done on nonhospitalisation alternatives in the crisis intervention field (Bond et al, 1989). In the Bassetlaw flat a sociotherapy alternative to admission has been developed although we do admit that the patients are a well-screened group (the results of a poorly considered admission into an unstaffed flat could be catastrophic). Even so, there are numerous advantages in dealing with this group of patients without resorting to hospital admission. Stigmatisation is avoided and self-esteem and coping behaviour are built up. The peace and quiet of the flat often contrasts strongly with the chaos of the domestic situation and foster more enthusiastic day hospital participation and problem-solving behaviour.

A review of strategic mental health plans (Kingdon, 1989) revealed that only 13 out of 127 plans mention proposals for crisis accommodation. An unstaffed flat can not only help to fulfil this need but also provide a useful rehabilitation option.

\section{References}

BOND, G. R., WITHERIDGE, T. F., WASMER, D. et al (1989) A comparison of two crisis housing alternatives to psychiatric hospitalisation. Hospital and Community Psychiatry, 40, 177-183.

KingDON, D. G. (1989) Mental health services: results of a survey of English district plans. Psychiatric Bulletin, 13, 77-78.

LEFF, J., KUIPERS, L., BERKowitz, R., et al (1982) A controlled trial of social intervention in the families of schizophrenic patients. British Journal of Psychiatry, 141, 121-134.

World Health Organization (1978) Mental Disorders: Glossary and Guide to their Classification in accordance with the ninth revision of the International Classification of Diseases. Geneva: World Health Organization. 